\title{
Electromechanical Transmission of Skid Steer Loader
}

\author{
Alexey Khomichev ${ }^{1, ~ *}$ and Alexandr Volkov ${ }^{1}$ \\ ${ }^{1}$ Kurgan state university, Faculty of Transport Systems, Department of Tracked Vehicles and Applied \\ Mechanics, 640020, Kurgan, Russia
}

\begin{abstract}
The article analyzes the power train components of skid steer loaders. The choice of the scheme and the design of the transmission units of the loader with a traction electric drive is substantiated. The results of calculating the traction characteristic of the straight-line movement of the loader taking into account different values of the coefficient of resistance to movement are presented.
\end{abstract}

\section{Introduction}

Currently, there is a trend towards the transition of vehicles to alternative environmentally friendly energy sources, one of which is the electric motor. Many works have been devoted to the creation and application of vehicles with a traction electric motor. [1-7] Machines with an electric motor also exist in the field of municipal cleaning and road construction equipment. [8-11]

Skid steer loaders are used in the construction and repair of roads, maintenance and cleaning of urban areas, in warehouses. Under these operating conditions, the use of a traction electric motor instead of an internal combustion engine is preferable due to its advantages:

- Zero emissions, which has a positive effect on the ecology of cities and allows you to work indoors.

- Almost silent operation, which also has a beneficial effect on the environment and allows you to use the forklift at night and early morning hours.

Modern skid steer loaders are equipped with a diesel internal combustion engine and hydrostatic transmission. [12] To create a loader with an electric traction drive, it is necessary to replace the hydrostatic transmission with an electromechanical one.

\section{Purpose and objectives of design}

The purpose of the skid steer loader design is to create a machine that will match the performance of an internal combustion engine loader. For the developed loader, it is necessary to justify the choice of the following components:

\footnotetext{
* Corresponding author: khomichev.alexey@mail.ru
} 
- Traction electric motor - an electric motor designed to propel vehicles by converting electrical energy stored in storage devices into mechanical energy.

- Mechanical gearbox designed to reduce the number of revolutions, convert torque and transmit it to the drive wheels. off.

- Parking brake designed to hold the loader in place when the traction motor is powered

\section{Traction motor selection}

For loaders equipped with a hydrostatic transmission, two hydraulic motors are installed one on each side. This solution allows for the best implementation of the side turning scheme. It is also advisable to use two traction motors on the designed loader. Comparison of the technical characteristics of the skid steer loaders power train components is presented in table 1 .

Table 1. Technical characteristics of the transmission components

\begin{tabular}{|l|c|c|c|}
\hline \multicolumn{1}{|c|}{ Name } & MKSM-800H & Termit 1000 & Developed loader \\
\hline Motor type & Axial piston & Radial piston & $\begin{array}{c}\text { Permanent magnet } \\
\text { synchronous }\end{array}$ \\
\hline Motor model & MPA-33 & MS 05 & EMRAX 228 \\
\hline Rotation speed, rpm & 1500 & 220 & 3000 \\
\hline Rated power, kW & 19,2 & 29 & 28 \\
\hline Maximum power, kW & 64,4 & 50 & 100 \\
\hline Rated torque, $\mathrm{N}^{*} \mathrm{~m}$ & 121,6 & 2285 & 120 \\
\hline Maximum torque, $\mathrm{N}^{*} \mathrm{~m}$ & 183,6 & 3200 & 230 \\
\hline Efficiency, \% & 86 & 89 & $92 \ldots 97$ \\
\hline Diameter/width, mm & $190 / 340$ & $232 / 206$ & $228 / 86$ \\
\hline Weight, kg & 30 & 41 & 12,4 \\
\hline
\end{tabular}

Based on the results of a comparative analysis of electric motor [5] and traction calculation, the EMRAX 228 electric motor was selected. The selected electric motor, with its small dimensions and weight, has high values of the developed power and torque. [13] View and section of the EMRAX 228 electric motor is shown in Figure 1.
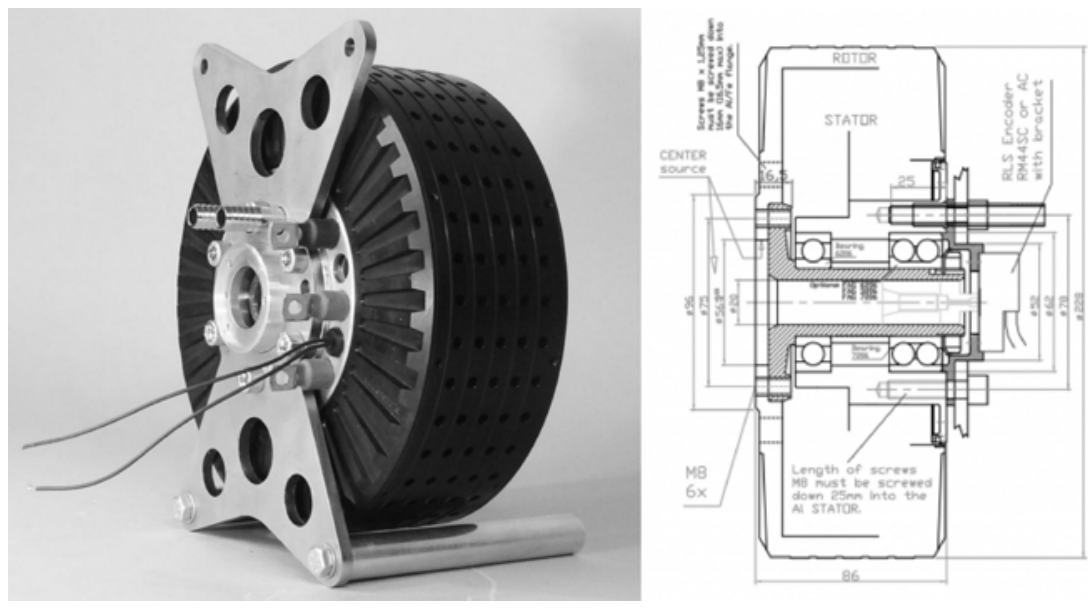

Fig. 1. The view and section of the electric motor EMRAX 228 


\section{Calculation of the traction characteristic and the choice of the kinematic scheme of the transmission}

The mechanical part of the transmission of loaders with a hydrostatic transmission includes a gearbox designed to increase the torque and transfer it to the wheels of the machine. The type and number of gear stages is determined by the value of the torque on the shaft of the hydraulic motor.

To provide the required tractive effort on the wheels of the MKSM-800H loader, in combination with axial piston hydraulic motors, four-stage gear reducers are used, including one bevel gear and six spur gears. The hydrostatic transmission of the Termit 1000 loader uses high-torque radial piston motors and chain drives. The maximum travel speed of these loaders is $12 \mathrm{~km} / \mathrm{h}$. Loader transmission parameters are shown in the table 2 .

Table 2. Skid steer loader transmission parameters

\begin{tabular}{|l|c|c|c|}
\hline \multicolumn{1}{|c|}{ Name } & MKSM-800H & Termit 1000 & Developed loader \\
\hline Number of gear & 4 & 1 & 2 \\
\hline $\begin{array}{l}\text { First stage transmission } \\
\text { type }\end{array}$ & Bevel gear & Chain drive & Planetary gear \\
\hline $\begin{array}{l}\text { Second and subsequent } \\
\text { stage transmission type }\end{array}$ & Spur gear & - & Chain drive \\
\hline Gear ratio & 21,1 & 2,5 & 16,2 \\
\hline
\end{tabular}

Based on the analysis carried out in the transmission of the developed loader, it was decided to use a planetary gear as the first stage and a chain drive as the second stage. This allows you to provide the required tractive effort on the wheels of the loader, as well as to achieve the following advantages:

- Higher efficiency compared to multistage gearbox.

- Less noise generated by chain drive.

- The possibility of unification of chain drive units with a serially produced loader.

The kinematic diagram of the transmission of the developed loader is shown in Figure 2 .

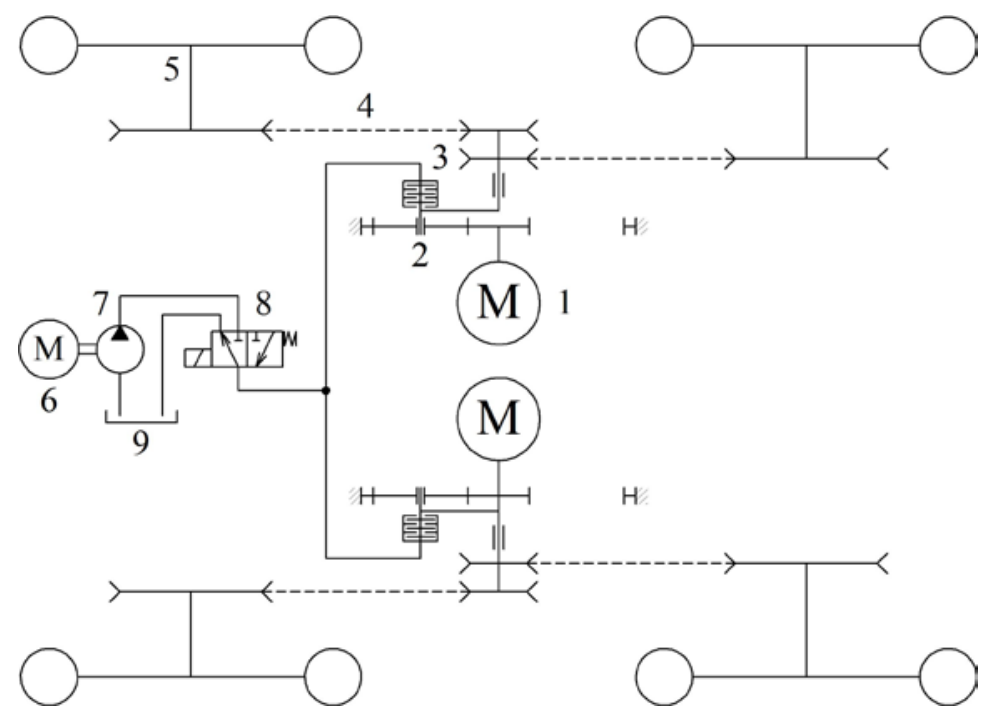

Fig. 2. The kinematic diagram of the loader transmission 
The transmission ratio has been selected to provide the required traction force and the maximum travel speed of the loader. In this case, the gear ratio of the planetary gear was calculated based on the possibility of unification with the chain drive of the Termit 1000 loader. For the selected traction motor and transmission kinematic scheme, the traction characteristic was calculated.

The results of calculating the dynamic factor are shown in Figure 3.

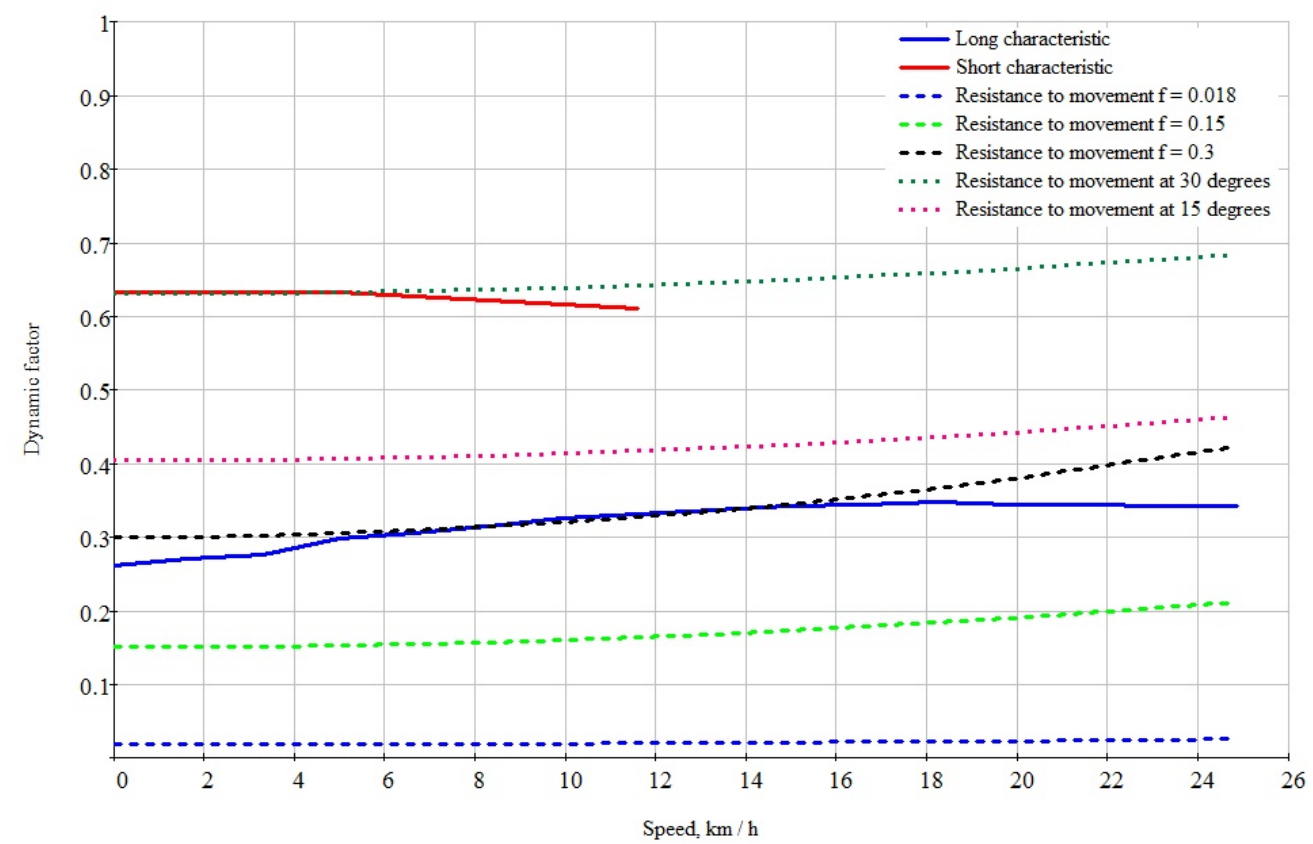

Fig. 3. The dynamic factor of the skid steer loader

Analyzing the results obtained, the following conclusions can be drawn:

1) the maximum travel speed of the loader on the asphalt concrete road (rolling resistance coefficient $\mathrm{f}=0.018)-24.8 \mathrm{~km} / \mathrm{h}$;

2) the maximum speed of the loader with a load on a dry dirt road (rolling resistance coefficient $\mathrm{f}=0.15)-8.9 \mathrm{~km} / \mathrm{h}$;

3) the maximum speed of a loader with a load on wet sand or virgin snow (rolling resistance coefficient $\mathrm{f}=0.3$ ) $-4.5 \mathrm{~km} / \mathrm{h}$;

4) the maximum traction force on the loader wheels - $19693 \mathrm{~N}$ (when the electric motor is operating at a short-term characteristic).

\section{Justification and selection of the design of transmission components}

\subsection{Planetary gearbox}

To ensure the required gear ratio, a planetary gearbox scheme with a fixed epicycle and a carrier as an output link was chosen. The module and the number of teeth of the gears were selected in such a way that the overall dimensions of the gearbox housing did not exceed the height of the chain drive housing and provide the possibility of assembling the gearbox in the loader frame. At the same time, the necessary safety factors were also provided. View and section of the planetary gearbox is shown in Figure 4. 


\subsection{Parking brake}

In the hydrostatic transmission of skid steer loaders, the parking brake is mounted on the motor shaft. Typically, this is a normally closed, hydraulically controlled multi-disc friction unit. The Belleville spring acts through the piston on the friction plate pack, thereby creating the necessary braking torque to hold the truck in place. After starting the engine and supplying the working fluid with the required pressure to the brake booster, the piston moves and stops compressing the friction discs. In this case, the shaft of the hydraulic motor can rotate, and the loader can start moving.

The designed loader also uses a normally closed multi-disc parking brake. It is located inside the body of the planetary gearbox and, when the power supply of the loader's electrical system is turned off, it holds the planetary carrier stationary (Figure 4).
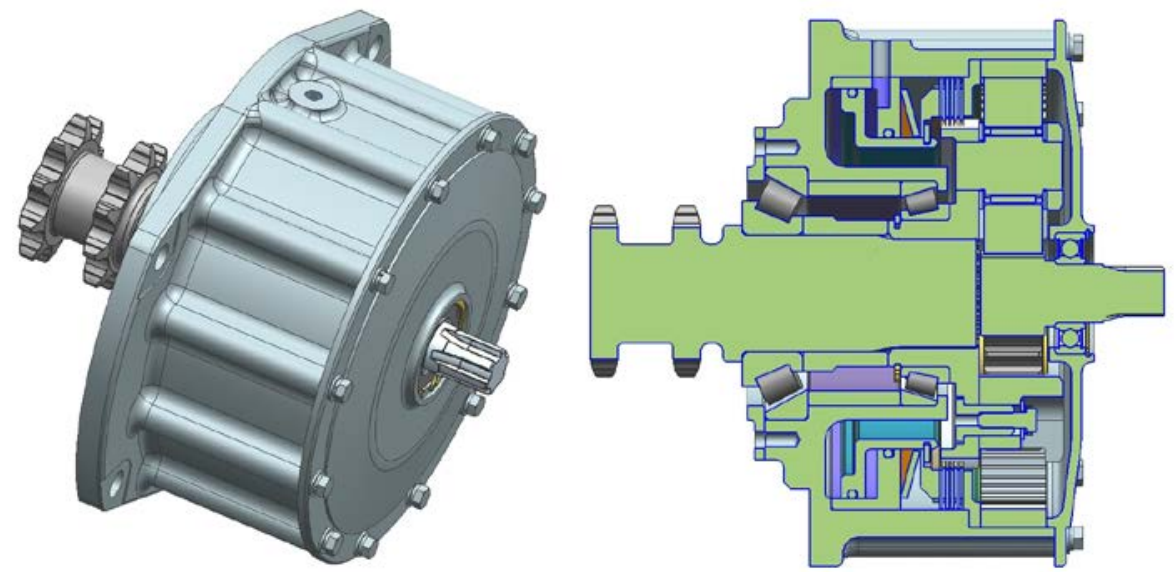

Fig. 4. The view and section of the planetary gearbox

To disengage the parking brake, the working fluid of the hydraulic system of the working equipment of the loader is used. The fluid supply to the brake booster is carried out by a pump driven by an electric motor operating from a voltage of $12 \mathrm{~V}$.

When the power of the on-board network of the loader is turned on, self-diagnosis of the machine systems takes place, the electric motor 6 turns on and the pump 7 starts to supply the working fluid through the blocking valve 8 to the tank 9 (Figure 2). After disabling the loader movement blocking valve 8 goes to the "work" position, the working fluid is supplied under the required pressure to the boosters 3 of the brakes of the left and right planetary gearboxes 2 . Electric motors 1 can transmit torque through planetary gearboxes 2 and chain drives 4 to wheels 5 of the loader.

\section{Conclusions}

As a result of the analysis, calculations and design studies for the developed loader, EMRAX 228 traction motors and the mechanical transmission, which includes a planetary gearbox and a chain drive, were selected. The design of a parking brake with an electrohydraulic cut-off drive is proposed.

The power plant and transmission allow the loader to develop a maximum tractive effort of $19693 \mathrm{~N}$, a maximum speed of $24.8 \mathrm{~km} / \mathrm{h}$ on an asphalt road, and a maximum speed of $8.9 \mathrm{~km} / \mathrm{h}$ with a load on a dirt road.

The obtained characteristics are superior to most of the implemented designs of skid steer loaders with an internal combustion engine and hydrostatic transmission. Maximum 
travel speed over $15 \mathrm{~km} / \mathrm{h}$ for a loader with a hydrostatic transmission is only possible when using two-volume hydraulic motors. The developed loader achieves an optimal combination of traction and speed characteristics, which results in a more versatile and efficient machine.

\section{References}

1. Design of car transmissions: Handbook / Under total. ed. A.I. Grishkevich. - M.: Mechanical Engineering, 1984, - 272 p.

2. Modeling of vehicle systems: Textbook / M.M. Zhileikin, G.O. Kotiev. - M.: Publishing house of MSTU im. N.E. Bauman, 2017, - 240 p.

3. Fundamentals of electric drive: textbook / A.B. Krasovsky. - Moscow: Publishing house of MSTU im. N.E. Bauman, 2015. - 405 p.

4. K. Evseev, A. Dyakov, V. Pushtakov, Analysis and design solutions for a $4 \times 4$ ATV with an electromechanical transmission. MATEC Web of Conferences 329, 01022 (2020). DOI: 10.1051/matecconf/202032901022.

5. K. Evseev, A. Dyakov, K. Popova, Analysis of the electric motor and transmission for a 4x4 ATV. MATEC Web of Conferences 329, 01019 (2020). DOI: 10.1051/matecconf/202032901019.

6. Y. Sun, M. Li, C. Liao, Analysis of wheel hub motor drive application in electric vehicles. MATEC Web of Conferences 100, 01004 (2017). DOI: 10.1051/matecconf/201710001004.

7. J. Caban, J. Vrabel, B. Šarkan, J. Zarajczyk, A. Marczuk. Analysis of the market of electric tractors in agricultural production. MATEC Web of Conferences 244, 03005 (2018). DOI: 10.1051/matecconf/201824403005.

8. https://www.kovacoelectric.com/en/elise-900

9. https://www.buchermunicipal.com/int/products/sweepers/compact-sweepers/citycat$\underline{\mathrm{v} 20 \mathrm{e}}$

10. https://www.tenaxinternational.com/en/prodotto/electra-2-0-evos/

11. https://dzero2.dulevo.com

12. A. Khomichev, A. Volkov Chassis design of skid steer loaders. IOP Conf. Series: Materials Science and Engineering 709, 033012 (2020).

13. https://emrax.com/e-motors/emrax-228/ 